\title{
Double-masked trial of topical acyclovir and steroids in the treatment of herpes zoster ocular inflammation
}

\author{
R J Marsh, M Cooper
}

\begin{abstract}
Ninety seven new patients with ophthalmic zoster were randomly allocated to three topical treatment groups: acyclovir (ACV) ointment and placebo drops (AP), placebo ointment with steroid drops (PS), and acyclovir ointment with steroid drops (AS). The dosage administered was determined by the score of the ocular inflammation. Follow-up was for at least one year. The results showed that topical ACV alone is insufficient for severe ocular inflammation but is not inclined to lead to recurrences in milder cases. Topical steroid alone is effective but tends to necessitate prolonged treatment. Combined steroid and $\mathrm{ACV}$ is questionably better than steroid alone and causes marginally fewer rebound inflammations.
\end{abstract}

Ophthalmic zoster has been said to give rise to ocular complications in $50 \%$ of patients. ${ }^{1}$ These are chiefly inflammatory and range from being mild, such as episcleritis, to severe, such as sclerokeratitis and hypertensive iritis. The mechanisms of these complications are poorly understood but clearly involve replication of the varicella/zoster virus in the early stages and then the inflammatory response. The latter is conventionally treated with topical steroid, ${ }^{2}$ which, though usually effective, may have to be continued for long periods, as inflammation tends to reappear during or shortly after withdrawal.

On the other hand, viral replication may be limited early on by acycloguanosine (acyclovir or $\mathrm{ACV}$ ), a potent and selective inhibitor of viruses of the herpes group, in particular herpes simplex virus types 1 and 2 and to a less extent varicellazoster virus (VZV). ${ }^{34}$ The intraocular penetration of topical ACV is superior to that of other antiviral agents ${ }^{5}$ and would therefore make it the rational choice. An open study of topical acyclovir on 18 patients with a short follow-up ${ }^{6}$ showed it controlled keratoconjunctivitis in 15 of the patients without topical steroid, and there was no recurrence on stopping treatment. A further study comparing topical ACV and steroid reported ACV to be superior to steroid in terms of the median healing time of corneal epithelial ulcers, but there was no significant difference for stromal lesions, uveitis, or scleritis. ${ }^{7}$ Of the patients on steroid $63 \%$ had a recurrence of ocular inflammation during or after withdrawal of therapy, making the mean treatment time in the steroid treated group significantly longer than in the ACV group.

These results did not correspond with our experience of ACV at Moorfields, ${ }^{8}$ where half of our patients, despite being treated early with it, developed very serious ocular inflammation necessitating and responding well to topical steroids (admittedly with attendant liability to relapse). Moreover, in our experience mild disease such as corneal microdendritic ulcers, some nummular keratitis, and most cases of episcleritis are self-limiting and do not require any treatment. Therefore we consider that ACV does not have any effect in these cases and steroid could be positively harmful.

The mechanisms by which rebounds in ocular disease may follow steroid withdrawal are still uncertain. Steroids can enhance viral replication ${ }^{9}$ by the suppression of some of the inflammatory responses. It is not known whether the chronic or relapsing ocular lesions in zoster are dependent on viral replication or the presence of some sort of antigen. Perhaps it is significant that, although replicating virus is present in the acute epithelial lesions of zoster, ${ }^{10}$ so far as we know replicating virus has not been identified or cultured in pathological specimens from chronic cases. It would therefore seem logical to try an antiviral during the acute phases of the disease but less certainly in the later phases.

The use of ACV and steroids, separately or in combination, compared with placebo in the treatment of herpes zoster ocular inflammation has not previously been examined in a controlled clinical trial. We considered the large number of patients we see and the doubts raised by our observations justified such a three-armed double blind trial.

\section{Patients and methods}

New patients presenting at Moorfields Eye Hospital with ophthalmic zoster were offered inclusion in the trial. Patients excluded were those who did not give their consent, were unwilling or unable to attend regularly for clinical assessment, were under 18 years, had received antivirals or steroid by any route, had other significant ocular pathology, had no eye disease at all, and had had the onset of the rash over 3 weeks previously.

Patients willing to take part were informed of the nature of the trial and gave their written consent.

The trial was double masked and randomised. Patients eligible for entry were randomly allocated to receive either acyclovir ophthalmic ointment and placebo eye drops (AP), placebo ointment and steroid eye drops (PSI), or acyclovir ophthalmic ointment and steroid eye drops (AS).

On admission to the trial the following details were recorded: time from onset of rash, preceding ocular therapy, other eye disease, previous glaucoma or family history of glaucoma, and whether eye involvement was mild, moderate, or severe. 
Table 1 Score card for recording inflammatory index

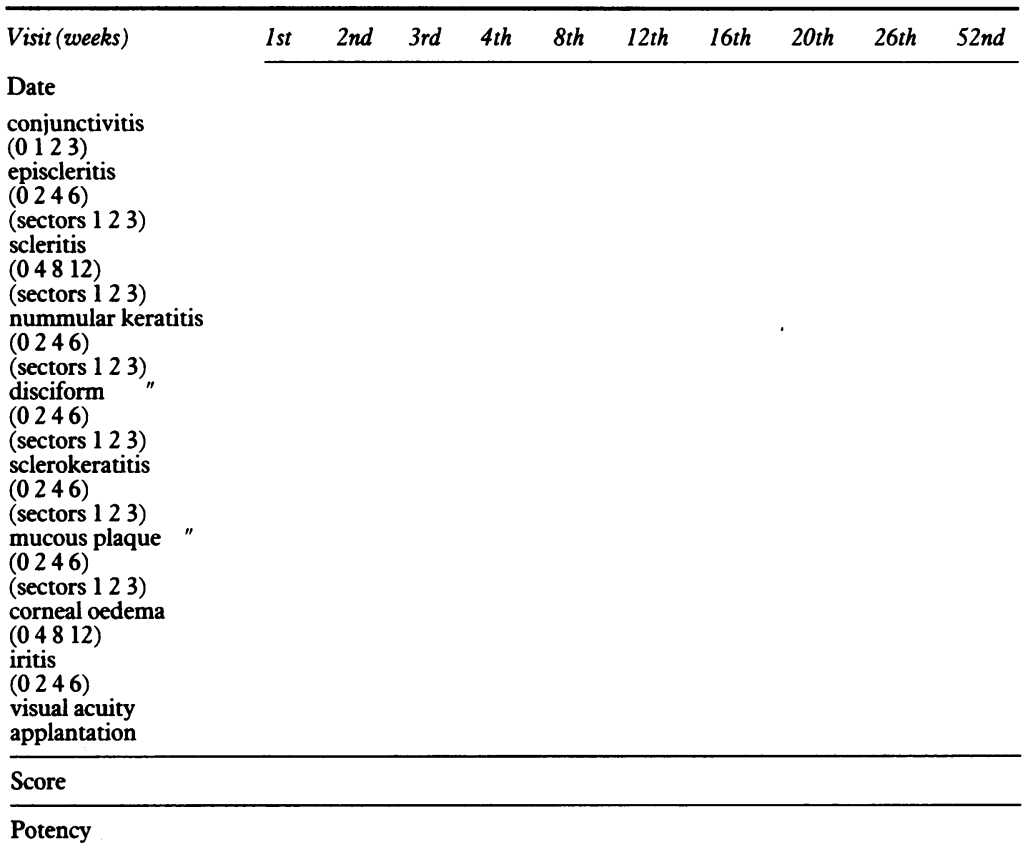

A scoring system of the degree of inflammation of the eye was devised in order to calculate the intensity of treatment to be used. In essence each inflammatory lesion was scored as follows: no lesion ( 0$)$, mild (1), moderate (2), and severe (3), and all scores were added together to reach a total. However, we considered from clinical experience that this basic scoring system was inadequate alone to indicate appropriate intensity of treatment, particularly with reference to steroids. This is because lesions are often multifocal in several sectors, and certain inflammatory conditions require high doses of topical steroid to control them. For instance, conjunctivitis is a very mild and transient condition responding readily to a low dose of steroid, whereas scleritis and corneal oedema are severe and require intensive topical steroid to control them. There are other conditions of intermediate severity such as episcleritis and nummular keratitis. We therefore modified the scoring to bring it into line with the most appropriate intensity of treatment and thus quadrupled the score of scleritis and doubled that of the intermediate group. We also added a score of 1 for one sector, 2 for two sectors, and 3 for more than two sectors. Table 1 shows the inflammatory score sheet where the inflammatory indices of the ocular complications were recorded and totalled.

Table 2 gives the therapeutic regimen based on these different scores. All patients with scores over 16 had the most intensive treatment possible, and at each visit the scores were reassessed and the dosage adjusted accordingly. When the score fell below 5 ointment was stopped. This was because Wellcome considered that ACV became relatively ineffective at doses less than three times a day. The drops, however, were continued because even minute doses of steroid appear to have a therapeutic effect. Once signs of active ocular inflammation had ceased, treatment was continued at the minimum dose for at least three months and halved after that for a
Table 2 Dosage regimen

\begin{tabular}{llll}
\hline $\begin{array}{l}\text { Log dilution } \\
\text { of drop }\end{array}$ & $\begin{array}{l}\text { Ointment } \\
\text { frequency }\end{array}$ & Score & Potency \\
\hline $0 \cdot 1 \% \times 6 /$ day & $\times 5$ & $13+$ & 1 \\
$0 \cdot 1 \% \times 4 /$ day & $\times 4$ & $11-12$ & 2 \\
$0 \cdot 1 \% \times 3 /$ day & $\times 3$ & $9-10$ & 3 \\
$0 \cdot 03 \% \times 3 /$ day & $\times 3$ & $7-8$ & 4 \\
$0 \cdot 01 \% \times 3 /$ day & $\times 3$ & $5-6$ & 5 \\
$0 \cdot 01 \% \times 2 /$ day & Nil & $3-4$ & 6 \\
$0 \cdot 01 \% \times 1 /$ day & Nil & $1-2$ & 7 \\
\hline
\end{tabular}

further two months to cover any rebound phenomenon.

A $1 \mathrm{~cm}$ ribbon of $3 \%$ acyclovir ointment or placebo was administered on to the lower tarsal conjunctiva. Dilutions of dexamethasone drops at $0.1 \%, 0.03 \%$, and $0.01 \%$ were prepared with matching placebo. One drop was instilled at a time. ACV ointment and matching placebo were packaged and labelled by Wellcome. The placebo consisted of the same ingredients as the drug formulation, without the ACV. Steroid eye drops and matching placebo were prepared and labelled by the pharmacy at Moorfields Eye Hospital. The placebo consisted of the diluent used in the preparation of the steroid drops and was labelled $0 \cdot 1 \%, 0.03 \%$, and $0.01 \%$.

Patients were seen as often as clinically necessary but at least twice in the first week of presentation, weekly thereafter until the end of the first month, and then at monthly intervals intil the end of therapy. The clinical proformas and score sheets were completed on each occasion, the total inflammatory score calculated, and the appropriate treatment administered. Any adverse symptoms or signs potentially attributable to the therapy were carefully documented in the adverse reactions chart. Final assessments were made at six and 12 months following resolution of active ocular involvement.

Patients were withdrawn from the trial if signs of toxicity or side effects developed, if they deviated seriously from the protocol, or if their ocular complications progressed despite full therapy (potency 1). The last was taken as when the ocular inflammatory score continued to rise over a three-day period or more on full therapy. Then the patient was placed on full strength dexamethasone at least six times a day to prevent any scarring of the eye. We continued to monitor all patients withdrawn from the trial.

Any recurrence of ocular complications

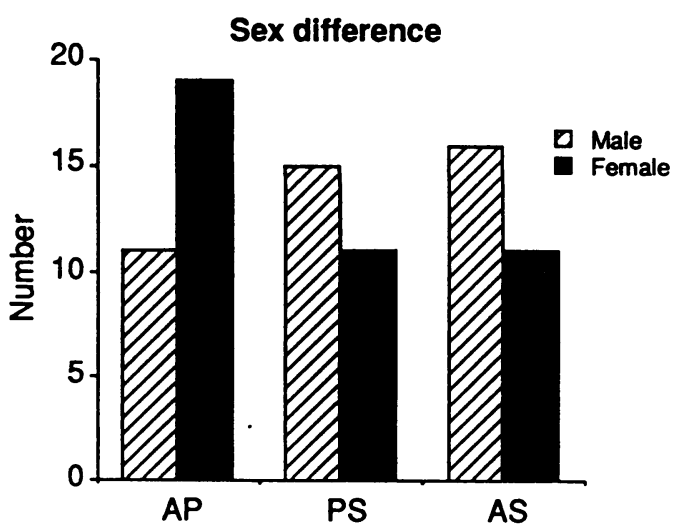

Figure 1 Sex distribution of the patients in the three groups. 


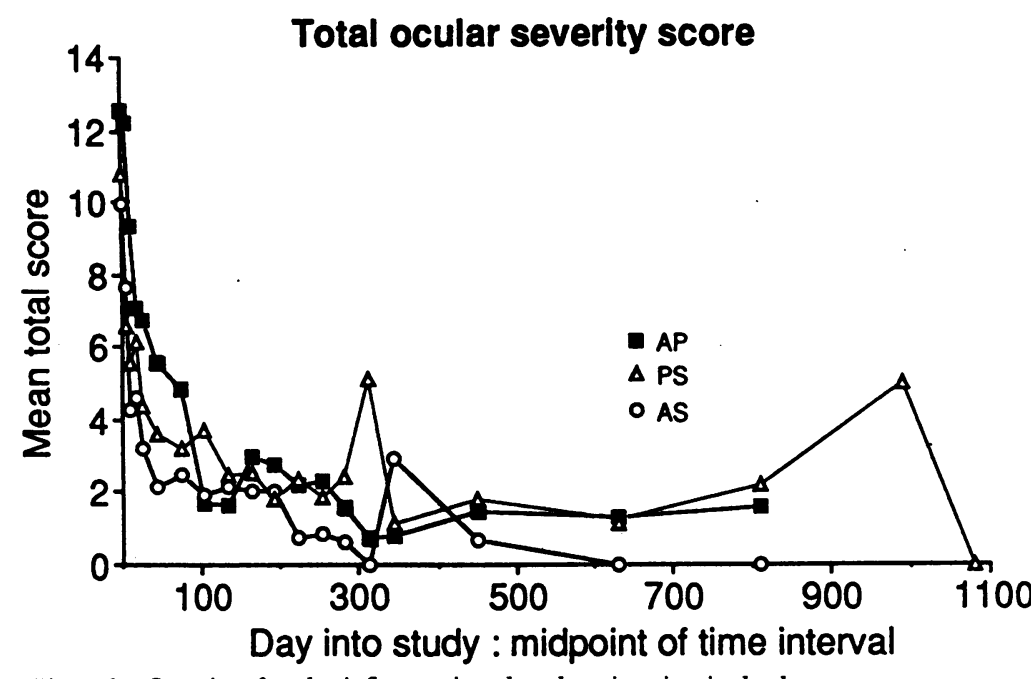

Figure 2 Severity of ocular inflammation plotted against time in the three groups.

during the period in which the frequency of administration of the treatment was being reduced was treated in accordance with the inflammatory scoring and the drug dosage appropriately increased. Any recurrence that occurred after the end of therapy was treated similarly.

\section{Results}

The original intention was to recruit 120 patients, but this proved impracticable. The main reason was that in the later stages of the trial a large proportion of patients presenting to the Accident and Emergency Department had already been started on some form of ACV by their general practitioners. This made recruitment increasingly slow and those recruited increasingly unrepresentative. It was therefore decided to limit the numbers to 97 . Of these, 14 sets of results could not be used because of inadequate documentation or follow-up; 30 patients remained in the $\mathrm{ACV} /$ placebo (AP)

Table 3 Ocular inflammatory complications in patients with ophthalmic zoster treated with topical acyclovir and placebo, topical steroid and placebo, topical steroid and acyclovir

\begin{tabular}{|c|c|c|c|}
\hline & $\begin{array}{l}A P \\
\text { ACV/placebo } \\
\text { (30 patients) }\end{array}$ & $\begin{array}{l}\text { PS } \\
\text { Placebo/steroid } \\
\text { (26 patients) }\end{array}$ & $\begin{array}{l}\text { AS } \\
\text { ACV/steroid } \\
\text { (27 patients) }\end{array}$ \\
\hline \multicolumn{4}{|l|}{ Conjunctivitis } \\
\hline $\begin{array}{l}\text { present at entry } \\
\text { mean baseline score }\end{array}$ & ${ }_{1.7}^{27}$ & $\begin{array}{l}24 \\
1 \cdot 5\end{array}$ & $\stackrel{26}{1 \cdot 5}$ \\
\hline \multicolumn{4}{|l|}{ Episcleritis } \\
\hline $\begin{array}{l}\text { present at entry } \\
\text { mean baseline score } \\
\text { mean no. of sectors }\end{array}$ & $\begin{array}{c}29 \\
3 \cdot 2 \\
2 \cdot 7\end{array}$ & $\begin{array}{l}26 \\
2 \cdot 9 \\
2 \cdot 5\end{array}$ & $\begin{array}{l}27 \\
2 \cdot 9 \\
2 \cdot 3\end{array}$ \\
\hline \multicolumn{4}{|l|}{ Nummular keratitis } \\
\hline $\begin{array}{l}\text { present at entry } \\
\text { mean baseline score } \\
\text { mean no. of sectors }\end{array}$ & $\begin{array}{l}7 \\
0 \cdot 7 \\
0.4\end{array}$ & $\begin{array}{l}5 \\
0.5 \\
0.2\end{array}$ & $\begin{array}{l}6 \\
0.3 \\
0.3\end{array}$ \\
\hline \multicolumn{4}{|l|}{ Disciform keratitis } \\
\hline $\begin{array}{l}\text { present at entry } \\
\text { mean baseline score } \\
\text { mean no. of sectors }\end{array}$ & $\begin{array}{l}1 \\
0.1 \\
0.03\end{array}$ & $\begin{array}{l}1 \\
0 \cdot 2 \\
0 \cdot 1\end{array}$ & $\begin{array}{l}1 \\
0 \cdot 1 \\
0 \cdot 1\end{array}$ \\
\hline \multicolumn{4}{|l|}{ Sclerokeratitis } \\
\hline $\begin{array}{l}\text { present at entry } \\
\text { mean baseline score } \\
\text { mean no. of sectors }\end{array}$ & $\begin{array}{l}1 \\
0 \cdot 1 \\
0.03\end{array}$ & $\begin{array}{l}1 \\
0 \cdot 1 \\
0.1\end{array}$ & $\begin{array}{l}2 \\
0 \cdot 2 \\
0 \cdot 1\end{array}$ \\
\hline \multicolumn{4}{|l|}{ Mucous plaque keratitis } \\
\hline $\begin{array}{l}\text { present at entry } \\
\text { mean baseline score } \\
\text { mean no. of sectors }\end{array}$ & $\begin{array}{l}2 \\
0 \cdot 1 \\
0 \cdot 1\end{array}$ & $\begin{array}{l}0 \\
0 \\
0\end{array}$ & $\begin{array}{l}2 \\
0 \cdot 1 \\
0 \cdot 04\end{array}$ \\
\hline \multicolumn{4}{|l|}{ Corneal oedema } \\
\hline $\begin{array}{l}\text { present at entry } \\
\text { mean baseline score }\end{array}$ & $\begin{array}{l}8 \\
1 \cdot 5\end{array}$ & $\begin{array}{l}5 \\
0.9\end{array}$ & $\begin{array}{l}3 \\
0.7\end{array}$ \\
\hline \multicolumn{4}{|l|}{ Iritis } \\
\hline $\begin{array}{l}\text { present at entry } \\
\text { mean baseline score }\end{array}$ & $\stackrel{21}{1.9}$ & $\begin{array}{l}14 \\
1.7\end{array}$ & $\stackrel{11}{1 \cdot 0}$ \\
\hline
\end{tabular}

Table 4 Time in days to resolution of ocular inflammation in those patients who healed (expressed as a mean)

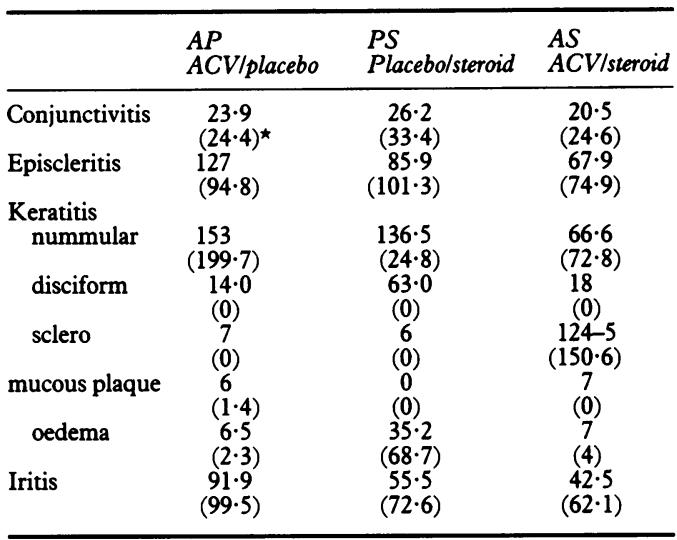

$\star S D$ in parentheses.

group, 26 in the steroid/placebo (PS) group, and 27 in the ACV/steroid (AS) group.

The sex distribution was significantly different between the groups (Fig 1), but we did not consider this had any relevance to the trial. A significant difference in severity of initial disease was noted, with the rounded mean initial clinical scores for the AP, PS, and AS groups being 13, 11 , and 10 respectively (Fig 2). Analysis shows that these scores were not strictly random. There was a bias towards more severe initial disease in the AP group because of a higher preponderance of severe uveitis and corneal oedema and towards less severe complications in the AS one.

There were no significant differences between the groups in terms of distribution of ocular complications (Table 3). For the more infrequent problems there would have been insufficient numbers.

Rates of healing are shown in Table 4. The rate was significantly poorer for episcleritis in group AP, whereas group AS showed faster resolution of inflammation overall, though the rate of severe complications was too low for any differences to be detected.

Table 5 gives the overall resolution of ocular inflammation. Treatment failure, that is when the full intensity of trial drug combinations failed to control inflammation, occurred in 12 out of 30 AP, two out of 26 PS, and three out of 27 AS $\left(\chi^{2}\right.$ test, $\mathrm{p}<0.01)$. In those patients whose condition failed to settle down it responded to intensive topical steroid and did not present any significant management problems.

Recurrences, either during tail-off or after stopping treatment, occurred in $3 / 16 \mathrm{AP}, 7 / 22$ $S P$, and 9/26 AS. The denominator is those who did not fail to respond to treatment ( $\chi^{2}$ test, $p>0.05)$. Treatment duration was over one year in 3/16 AP, 8/24 AS, and 3/24 AS. However, it should be noted that as 12 of the AP group were withdrawn because of treatment failure the

Table 5 Overall resolution of ocular inflammation

\begin{tabular}{llll}
\hline & $A P$ & $P S$ & $A S$ \\
& $A C V /$ placebo & Placebo/steroid & ACV/steroid \\
\hline Healed & 13 & 21 & 24 \\
Not healed & 17 & 4 & 2 \\
Unknown & 0 & 1 & 1 \\
\hline
\end{tabular}


milder ocular complications tended to remain in this group. Therefore there would be less tendency to relapses among them.

No difficulties were experienced with drop allergies, steroid induced rise of intraocular pressure, or other drug side effects.

\section{Discussion}

At their face value these results indicate that topical ACV alone is insufficient for severe ocular inflammation, takes longer to settle milder inflammation, but is not inclined to lead to recurrences in the milder cases. The results of the AP group would suggest that some acute ocular inflammations such as mild episcleritis and nummular keratitis are self limiting. Topical steroid alone is effective but prone to lead to prolonged treatment; whether it worsens ocular complications is not possible to say from these data. The combined ACV and steroid group is questionably better than the steroid alone in the short term and has a reduced number of patients with rebound inflammation, but this is not statistically significant. Interpretation of this trial is made difficult by the obvious initial differences between the groups. However, we have been assured by our statisticians that they do not account for the whole difference, and qualitatively the results are useful.

Having demonstrated the relative ineffectiveness of the topical ACV preparation there remain the systemic preparations which achieve better tissue concentrations. Controlled clinical trials have shown that ACV, given intravenously, significantly shortens the course of acute zoster skin rash, especially in immunosuppressed patients. ${ }^{411}$ It is also claimed that given orally at 600 and $800 \mathrm{mg}$ five times a day for 8-10 days at the start of the disease it significantly reduces the occurrence of ocular complications ${ }^{12}$ and postherpetic neuralgia. ${ }^{13}$ However, it must be said that the reported reduction of ocular complications is based on one multicentre trial with exclusion of cases with significant ocular inflammation at presentation, and the reduction of postherpetic neuralgia is a contentious issue depending on the definition of postherpetic neuralgia as opposed to acute neuralgia and on the normal incidence of neuralgia. ${ }^{14}$ Perhaps the next step is a three-armed clinical trial to decide whether a 10-day course of full dose oral ACV early on is more effective in reducing ocular inflammation than a placebo and systemic steroid. It should of course be borne in mind that the routine use of a systemic course of ACV has financial implications for health services.

It is at first sight surprising that antivirals are not more effective in zoster. The ocular complications of zoster presumably stem from the presence of $\mathrm{VZV}$, which initially is replicating, and the inflammatory response. Treatment can be directed to both components. The main difficulty is with timing and deciding which component is more significant. Another problem is gaining access to patients in the early stages of the disease. Unfortunately, chronic ocular inflammation may continue for years in some cases and is presumably not dependent on the presence of virus as we know it. Perhaps the virus at its active stage causes an antigenic change in the damaged tissues and remains there not replicating in an altered form, unidentifiable with conventional electron microscopy or culturing. So at a late stage of presentation (often the case) one would not expect conventional antivirals to work. Steroids on the other hand will suppress the inflammatory response causing tissue scarring at any stage and may be necessary in the long term if the antigenic stimulus continues. The latter would explain the difficulty in withdrawing the drug as opposed to steroids promoting survival of live virus in the tissues. The other disadvantages of steroid (glaucoma, cataract, and superinfections) should of course be borne in mind. ${ }^{2}$

It would be helpful at this stage to compare and contrast $\mathrm{HSV}$ and VZV virus. $\mathrm{HSV}$ is a more aggressive virus and replication is more signifcant in producing overall disease events than VZV. HSV can be found replicating in the eye at all stages of the disease, whereas VZV has been cultured only at the beginning. $\mathrm{HSV}$ is more sensitive in vitro to ACV than VZV. This would explain the poorer response of zoster to the drug. They both share an inflammatory component in their disease process which is double-edged; modifications by steroid is necessary to prevent scarring and optimise outcome. However, whereas antiviral cover is important with HSV to prevent corneal epithelial loss and stromal thinning, it is not strictly necessary with VZV. At this stage it is not clear whether antiviral cover in chronic HSV corneal stromal disease modifies the inflammation, but the seemingly better results in the AS group in this trial suggest there may be a positive benefit, though not quantifiable in zoster keratitis. It is interesting that chronic stromal keratitis in both conditions may be exquisitely sensitive to topical steroid: even $0.03 \%$ prednisolone drops on alternate days can be enough to control a potentially severe inflammation.

The general conclusions relating to management of zoster ocular disease are that mild inflammation does not require any treatment, whereas more severe problems do. In the long term a combination of ACV and steroid in the more severe complications may be appropriate to prevent relapses.

This trial gives only a general indication for treatment and cannot give a recipe, which will depend on individual characteristics. The finer judgments require an extensive knowledge of the natural and unnatural history of viral ocular disease and close observation. There is no single best treatment.

We thank Messrs Wellcome for their cooperation in designing, analysing results and providing ACV. We would especially like to thank David Grant for his help.

1 Edgerton AE. Herpes zoster ophthalmicus: report of cases and review of the literature. Arch Ophthalmol 1945; 34: 40-62, $114-53$.

2 Marsh RM. Current management of ophthalmic herpes zoster. Trans Ophthalmol Soc UK 1976; 96: 334-7.

3 Elion GB, Furman PA, de Miranda P, Beauchamp L, Schaeffer HJ. Selectivity of action of an antiherpetic agent 9-(2-hydroxyethoxy-methyl) guanine. Proc Natl Acad Sci USA 1977; 74: 5716.

4 Bean B, Braun C, Balfour HH. Acyclovir therapy for acute herpes zoster. Lancet 1982; ii: 118-21.

5 Poirier RH, Kingham JD, de Miranda P, Annil M. Intraocular viral penetration. Arch Ophthalmol 1982; 100: 1964-7. 
6 Mcgill J. Topical acyclovir in herpes zoster ocular involvement. Br F Ophthalmol 1981; 65: 542-5.

7 Mcgill J, Chapman C. A comparison of topical acyclovir with steroids in the treatment of herpes zoster keratouveitis. $\mathrm{Br} \mathcal{F}$ Ophthalmol 1983; 67: 746-50.

$8 \mathrm{Marsh}$ RJ, Cooper M. Acyclovir and steroids in herpes zoster keratouveitis. Br F Ophthalmol 1984; 68: 904.

9 Patterson A, Jones BR. The management of ocular herpes. Trans Ophthalmol Soc UK 1967; 87: 59-84.

10 Piebenga LW, Laibson PR. Dendritic lesions in herpes zoster ophthalmicus. Arch Ophthalmol 1973; 90: 268-70.
11 Peterslund NA, Ipsen J, Schonheyder H, et al. Acyclovir in herpes zoster. Lancet 1981; ii: 827-30.

12 Cobo IM, Foulks GN, Leisgang T, et al. Oral acyclovir in the treatment of acute herpes zoster ophthalmicus. Ophthalmology 1986; 93: 763-70.

13 McKendrick MW, McGill JL, Bell AM, et al. Oral acyclovir for herpes zoster. Lancet 1984; ii: 925 .

14 McKendrick MW, McGill JI, Wood MJ. Lack of effect of acyclovir on postherpetic neuralgia. Br Med $\mathcal{F} 1989$; 298: 431 .

\section{FIFTY YEARS AGO}

\section{Treatment of Mustard Gas Lesions of the Eye}

\section{To the Editors of}

THE BRITISH JouRnal of Ophthalmology.

DEAR SIRS-An instruction EMSI 252 (revised) on this subject has been widely distributed to the officers, consultants and hospitals of the Emergency Medical Service. It came before the Medical Board of Moorfields Eye Hospital 'for your information.' The Medical Board considered the instruction and felt that several points in it required comment.

1. The use of albucid solution is advised at First Aid Posts and at Hospitals in cases in which the eyes have been affected by gas vapour or gas splashing. It must be pointed out that the use of sulphanilamide preparations is not directed against gas contamination but only against subsequent infection of the conjunctiva and that opinion as to its efficiency in this latter respect is far from being generally favourable.
2. No mention is made in the instruction of the very diverse lesions which may be produced by gas, most of them slight and very few of them serious.

3. No indication is given of the treatment necessary when the cornea is definitely involved and while water is advised for irrigation of the eye at an incident and at First Aid Posts, no advice is given as to the lotion to be used for the irrigations recommended at Hospitals.

It would appear that this instruction is not in fact the 'result of further experience' and should be withdrawn and replaced by a carefully considered and detailed note based on actual experience obtained in the last war and on substantiated experimental evidence.

We are,

Yours faithfully.

F. A. JULER.

MAURICE WhITING. 